\title{
ASSOCIAÇÃO ENTRE O NÍVEL DE ESTRESSE E O NÍVEL EDUCACIONAL DE FUNCIONÁRIOS DE UMA UNIVERSIDADE PÚBLICA
}

Rayana Loch Gomes; Camila Balsamo Gardim; Aline Fernanda Barbosa Bernardo; Claudia Yuri Peffardini; Roselene Modolo Regueiro Lorençoni.

Fisioterapia, departamento de fisioterapia, FCT-UNESP. E-mail: Rayana.loch@hotmail.com

\section{RESUMO}

O estresse é considerado o mal do século, responsável por alterar o estado de saúde e o bem estar do indivíduo, podendo levar a diversas doenças. Associar o nível de estresse e o nível educacional de funcionários da FCT/UNESP - Campus de Presidente Prudente. A aplicação dos questionários foi realizada de forma padronizada em 38 voluntários, que foram orientados a questionar acerca de dúvidas que surgiram durante a aplicação. $O$ questionário possui 53 itens que questionam tanto sintomas físicos quanto psicológicos dos indivíduos. Foi aplicado o teste de Shapiro-Wilk e test t de Student, $p<0,05$. Estressores ocupacionais são ligados à organização do trabalho, como a pressão para a produtividade, condições de trabalho desfavoráveis, relação abusiva entre supervisor e subordinado, predispondo esse organismo ao mau funcionamento fisiológico, decorrente de tal estresse. O nível de estresse esta associado à baixa escolaridade nos funcionários desta universidade.

Palavras-chave: saúde, escolaridade, estresse, Lipp, trabalhadores.

\section{INTRODUÇÃO}

A palavra estresse na área da saúde foi empregada por Hans Selye em 1926, ao perceber que um grande número de pessoas sofria de várias doenças físicas e apresentavam queixas como fadiga, desânimo, hipertensão e falta de apetite (PAFARO et al., 2004). Em 1936 Selye utilizou o termo estresse para designar uma síndrome produzida por vários agentes nocivos, não existindo uma resposta específica do organismo, enfraquecendo-o e levando-o a adoecer (MARGIS et al., 2003; DAIAN et al., 2009).

O estresse é produto da interação do homem com o seu meio ambiente físico e sociocultural, ou seja, é uma condição psicofisiológica complexa que tem em sua origem a necessidade de enfrentar uma perturbação que ameace o equilíbrio interno do corpo (YANKER et al., 2007). Além disso, o estresse é considerado o mal do século, responsável por alterar o estado de saúde e bem estar do indivíduo que podem levar a doença e a morte. Há uma preocupação cada vez maior com a saúde dos trabalhadores para que os danos causados sejam amenizados ou evitados (PRETO et al., 2009). Segundo a Organização Mundial de Saúde (OMS) o estresse atinge 90\% da população. Na sociedade pós-moderna, o estresse tem se tornado um problema de saúde muito comum, atingindo o marco de $40 \%$ na população de São Paulo (SADIR et al., 2010). 
Nos dias atuais, o trabalho aparece como um importante fator gerador de estresse, já que na maioria das vezes, ele representa um desafio a ser vencido pelo trabalhador, no sentido de se manter atuante em um mercado de trabalho cada vez mais competitivo. Isso gera um grande desgaste tanto emocional quanto nas suas relações com o próprio trabalho (PRETO et a.I, 2010).

Um estresse contínuo no ambiente de trabalho constitui um importante fator determinante dos transtornos depressivos e outras doenças como a síndrome metabólica, ansiedade patológica, pânico, fobias, doenças psicossomáticas, síndrome da fadiga crônica, distúrbios do sono, diabetes e a síndrome de Burnout (SCHMIDT et al, 2009).

Segundo Sadir e Lipp (2009) "A presença do estresse pode ser explicada pela necessidade de adaptação às mudanças e ao ritmo da rotina que as pessoas estão sujeitas na atualidade, rotina esta que pode ser um dos fatores que explica o alto nível de estresse da população em geral. Estas mudanças contínuas, assim como as relações interpessoais que se estabelecem no ambiente de trabalho, podem gerar um alto nível de estresse também dentro das organizações, tornando-se fontes de stress ocupacional."

Um estudo publicado por Suehiro et al. (2008), avaliaram o nível de estresse e escolaridade, e por meio deste não evidenciaram correlação significativa entre as variáveis, com exceção fator pressão no trabalho. Segundo Miguel e Noronha (2009), esse fator apresentou índice muito baixo de correlação, o que, de maneira geral, impossibilita dizer que níveis diferentes de escolaridade apresentam níveis variados de estresse.

Estressores ocupacionais são ligados à organização do trabalho, como a pressão para a produtividade, retaliação, condições de trabalho desfavoráveis, indisponibilidade de orientação e treino, relação abusiva entre supervisor e subordinado, falta de controle sobre a tarefa e ciclos de trabalho e descanso incoerentes com o limite biológico. Tudo isso impõe ao indivíduo uma alta demanda, se o mesmo apresentar um repertório deficitário de enfrentamento, será desencadeado o estresse ocupacional. Quanto maior a demanda e menor o controle, mais provável que ocorra o estresse e prejuízos a saúde do trabalhador (MURTA et al., 2004).

Com as perdas humanas e econômicas associadas ao estresse ocupacional, tornam-se necessárias algumas intervenções para a sua prevenção ou controle, como programas de manejo de estresse podem ser focados na organização de trabalho e/ou no trabalhador. (MURTA et al, 2004). Diante disso, é necessário buscar medidas que avaliem os níveis de estresse, como o Inventário de Sintomas de Stress para Adultos de Lipp (ISSL). 


\section{OBJETIVO}

O objetivo desse estudo foi associar o nível de estresse e o nível educacional de funcionários da FCT/UNESP - Campus de Presidente Prudente.

\section{METODOLOGIA}

\section{Natureza da Pesquisa e Casuística}

O estudo se caracteriza como epidemiológico de corte do tipo transversal e a casuística do estudo foi composta por 38 funcionários da FCT- Unesp Campus Presidente Prudente. O critério de inclusão para a pesquisa foi estar em vínculo empregatício com a universidade.

Não foram inclusos no estudo indivíduos que se recusaram a colaborar com a coleta de dados, aqueles que não compreenderam o questionário aplicado. Os indivíduos foram devidamente informados sobre os procedimentos e objetivos deste estudo, e após concordarem, assinaram um termo de consentimento passando a fazer parte efetivamente do mesmo.

\section{Desenho do estudo}

Para realização da coleta de dados, os trabalhadores foram avisados com antecedência de 2 dias, via telefone, onde seriam entrevistados para a realização de um trabalho sobre estresse em funcionários da universidade. Inicialmente, foram explicados os objetivos do estudo e os voluntários que concordaram em participar do estudo assinaram o termo de consentimento livre e esclarecido (Protocolo número 103/2011). Após essa etapa, os indivíduos responderam em forma de entrevista o questionário proposto no estudo, esse realizado por uma equipe treinada.

\section{Coleta de dados}

A aplicação dos questionários foi realizada de forma padronizada e os voluntários foram orientados a questionar acerca de dúvidas que surgiram durante a aplicação.

\section{Instrumentos}

Para avaliação do estresse nos funcionários, foi aplicado o ISSL. O ISSL, validado em 1994 (LIPP et al., 1994), fornece uma medida objetiva da sintomatologia do estresse em jovens acima de 15 anos e adultos. Sua aplicação leva aproximadamente 10 minutos e pode ser realizada individualmente ou em grupos de até 20 pessoas. Não é necessário ser alfabetizado, pois os itens 
podem ser lidos para a pessoa. O Instrumento é formado por três quadros referentes às fases do estresse (ROSSETTI et al., 2008).

O primeiro quadro (Fase de Alerta), composto de 12 itens referente a sintomas físicos e 03 psicológicos que a pessoa tenha experimentado nas últimas 24 horas. 0 segundo quadro (Fase de Resistência e Quase-Exaustão) composto de 10 sintomas físicos e 05 psicológicos e está relacionado aos sintomas experimentados na última semana. E o terceiro quadro (Fase de Exaustão), composto de 12 sintomas físicos e 11 psicológicos, refere-se a sintomas experimentados no último mês. Alguns dos sintomas que aparecem no quadro 1 voltam a aparecer no quadro 3, mas com intensidade diferente (MARTINS et al., 2005).

No total, o ISSL apresenta 37 itens de natureza somática e 19 psicológicas, sendo os sintomas muitas vezes repetidos, diferindo somente em sua intensidade e seriedade. A fase 3 (quase-exaustão) é diagnosticada na base da frequência dos itens assinalados na fase de resistência (ROSSETTI et al., 2008).

O respondente marcando 7 itens ou mais, no quadro I, significa que se encontra em face de alerta; se marcar 4 itens ou mais, no quadro II, significa que se encontra na fase de resistência e se marcar 9 itens ou mais no quadro III o respondente encontra-se em fase de exaustão (KOLTERMANN et al., 2005).

\section{Análise dos Dados}

Para comparação características dos grupos, inicialmente, foi determinada a normalidade dos dados por meio do teste de Shapiro-Wilk. Onde foi constatada distribuição normal, aplicou-se o teste $\mathrm{t}$ de Student para dados não pareados. Já nas situações onde a distribuição normal não foi aceita, foi aplicado o teste de Mann-Whitney. Foram consideradas diferenças estatisticamente significantes quando o valor de " $p$ " for menor que 0,05 .

\section{RESULTADOS}

Na tabela é possível verificar a presença ou ausência de estresse segundo o nível educacional na população estudada. Os dados apresentados mostram uma porcentagem maior de estresse em indivíduos com níveis educacionais até o 2ำ Grau Completo, sendo representado por $64 \%$ da amostra. Osque se enquadram na escolaridade de 3 Grau ou superior apresentam menor porcentagem de estresse. 
Tabela 1. Presença ou Ausência de Estresse segundo nível educacional

\begin{tabular}{llcc} 
Nível Educacional & & $\mathbf{N = 3 8}$ & Porcentagem (\%) \\
\hline \multirow{3}{*}{ 10 a 2o Grau } & Estressado & 9 & 64 \\
& Sem Estresse & 5 & 36 \\
& Total & 14 & \\
\hline \multirow{3}{*}{ 3o Grau + } & Estressado & 6 & 25 \\
& Sem Estresse & 18 & 75 \\
& Total & 24 & \\
\hline
\end{tabular}

Tabela 2. Presença ou Ausência de Estresse segundo setor de trabalho

\begin{tabular}{cccc} 
Setor & & $\mathbf{N}=\mathbf{3 8}$ & Porcentagem (\%) \\
\hline \multirow{3}{*}{ Administração } & Estressado & 8 & 14,81 \\
& Sem Estresse & 19 & 70,37 \\
& Total & 27 & \\
\hline \multirow{2}{*}{ Docência } & Estressado & 1 & 14,29 \\
& Sem Estresse & 6 & 85,71 \\
& Total & 7 & \\
\hline \multirow{3}{*}{ Serviços Gerais } & Estressado & 2 & 50,00 \\
& Sem Estresse & 2 & 50,00 \\
& Total & 4 & \\
\hline
\end{tabular}

\section{DISCUSSÃO}

Os resultados encontrados no estudo indicam que o baixo nível de escolaridade esta associado ao maior nível de estresse. Condizente a isso, foi possível observar que na tabela $164 \%$ dos indivíduos pertencentes ao nível educacional de 1 으 e 2 으 apresentam-se estressados, enquanto que apenas $25 \%$ da população pertencente a níveis educacionais superiores encontram-se nessa situação.

Na tabela 2 relaciona-se a presença ou ausência de estresse segundo os setores de trabalho dos entrevistados (Administrativo, Docência e Serviços Gerais). Segundo a pesquisa, 8 (14\%) dos funcionários na Administração se encontram estressados, enquanto 19 não apresentam estresse. Na Docência encontra-se 1 (14\%) indivíduo estressado, enquanto outros 6 (85, 71\%) encontram-se sem estresse. Já nos funcionários dos Serviços Gerais, 2 (50\%) estão estressados enquanto 2 (50\%) não apresentam estresse. Proporcionalmente o setor de Serviços Gerais apresentou um maior número de indivíduos com estresse do que nos outros setores, mas não se pode afirmar nada dado ao número baixo de indivíduos nesse setor. 
Inúmeras pesquisas realizadas nas mais variadas partes do mundo apontam que o stress em excesso pode ocasionar no ser humano reações físicas e mentais, o que prejudica diretamente sua qualidade de vida e produtividade, sobretudo quando o indivíduo é exposto a níveis de tensões elevados por longos períodos de tempo, os quais acabam ultrapassando suas barreiras de resistência. Falar em stress é algo muito comum atualmente, contudo, compreendê-lo em sua constituição patológica requer um esforço maior, visto que esta doença que acomete milhares de pessoas ao redor de todo mundo possui características específicas, sobre as quais será discorrido neste estudo (CAMARGO et al, 2012).

Os indivíduos pesquisados são funcionários de uma universidade pública, porém, exercem diferentes tipos de funções, separados por Setor Administrativo, Docentes e funcionários de Serviços Gerais. Na literatura há estudos relacionando o estresse em diversas profissões específicas, como profissionais da saúde (Nogueira-Martins, 2002), policiais civis (Tamayo \& Tróccoli, 2002), enfermeiros (Stacciarini \& Tróccoli, 2002), professores (Codo, 2000). Apesar de não haver nível de significância estatisticamente aceitável nessa pesquisa, em futuras pesquisas com uma amostra maior desses três setores de trabalho diferentes pode obter-se algum significado estatisticamente válido, podendo-se analisar mais a fundo a diferença entre eles.

Uma explicação para que não ocorreram diferenças significativas entre as funções ocupadas pode ser que os indivíduos tenham experimentado apenas uma fonte externa e não houve um impacto muito grande no nível de estresse dos participantes, pois o estresse é causado tanto por fontes externas quanto internas como suas características pessoas (comportamento, estado de humor, assertividade, etc.). Segundo Sadir e Lipp (2002), podemos supor que as fontes internas podem ter tido influência significativa de como os indivíduos da pesquisa lidam com seu estresse no trabalho. Jacques e Codo (2002) ainda mostram que as características pessoais (individualismo e competitividade) agem de forma sinérgica com o ambiente organizacional estressante.

\section{CONCLUSÃO}

Pode-se concluir que o nível de estresse esta associado à baixa escolaridade nos funcionários desta universidade. Já a avaliação do nível educacional não foi encontrado relação estatisticamente significante, apesar de verificar um número percentual maior de indivíduos hipertensos no setor de serviços gerais dessa universidade. 


\section{REFERÊNCIAS}

CAMARGO, A.P; CARRAPATO, J.L.F. Relação existente entre nível de stress e perfil socioeconômico de gestante. Cadernos Brasileiros de Saúde Mental. v.4, n.10, p.105-133, 2012.

DAIAN, M.R.; PETROIANU, A.; ALBERT,I L.R. Avaliação do estresse psíquico em pacientes submetidos a operações de grande porte sob anestesia geral. Jornal Brasileiro de Psiquiatria, v.58, n.4, p.245-251, 2009. http://dx.doi.org/10.1590/S0047-20852009000400005

KOLTERMANN, I.T. Prevalência do Estresse Ocupacional em Trabalhadores Bancários. 205. 61f. (Dissertação Mestrado em Saúde e Comportamento) - Universidade Católica de Pelotas - UCPel. Pelotas.

LIPP, M.E.N.; GUEVARA, A.J.H. Validação Empírica do Inventário de Sintomas de Stress (ISS). Estudos Psicologia, v. 11, n.3, p. 43-9, 1994.

LIPP, M.E.N. Manual do Inventário de Sintomas de stress para Adultos de Lipp. 3rd ef. São Paulo: Casa do Psicólogo; 2005.

MARGIS, R.; PICON P.; COSNER, A.F.; SILVEIRA, R.O. Relação entre estressores, estresse e ansiedade. Revista de Psiquiatria, v.25, n.1, p.65-74, 2003.

MARTINS, M.G.T. Sintomas de Stress em Professores das Primeiras Séries do Ensino Fundamental: Um estudo exploratório. 2005. 193f. Dissertação (Mestrado em Ciências da Educação) - Universidade Lusófana de Humanidades e Tecnologias, Lisboa.

MIGUEL, F.K.; NORONHA, A. P. P. Estudo da relação entre inteligência emocional e estresse em ambientes de trabalho. Avaliação Psicológica, São Paulo, v. 8, n. 2, p. 219-228, 2009.

MURTA, S.G.; TRÓCCOLI, B.T. Avaliação de Intervenção em Estresse Ocupacional. Psicologia: teoria e pesquisa, v.20 n.1, p.39-47, 2004.

PAFARO, R.C.; MARTINO M.M.F.D. Estudo do estresse do enfermeiro com dupla jornada de trabalho em um hospital de oncologia pediátrica de Campinas. Revista Escola Enfermagem - USP, v.38, n.2, p.152-160, 2004. http://dx.doi.org/10.1590/S0080-62342004000200005

PRETO, V.A.; PEDRÃO, L.J. O estresse entre enfermeiros que atuam em Unidade de Terapia Intensiva. Revista Escola de Enfermagem, v.43, n.4, p.841-848, 2009. http://dx.doi.org/10.1590/S0080-62342009000400015

ROSSETTI, M.O., et al. O Inventário de Sintomas de Stress para Adultos de Lipp (ISSL) em Servidores da Polícia Federal de São Paulo. Revista Brasileira de Terapias Cognitivas, v. 4, n. 2, p. 108-119, 2008.

SADIR, M.A.; BIGNOTTO, M.M.; LIPP, M.E.N. Stress e Qualidade de Vida: influência de algumas variáveis pessoais. Paideia, v. 20, n. 45, p. 73-81, 2010.

SADIR, M.A.; LIPP, M.E.N. As Fontes de estresse no Trabalho. Revista de Psicologia da IMED, vol. 1, n. 1, p. 144-126, 2009. 
SCHMIDT, D.R.C.; DANTAS, R.A.S.; MARZIALE, M.H.P.; LAUS, A.M. Estresse ocupacional entre profissionais de enfermagem do bloco cirúrgico. TextoContextoEnfermagem, v.18, n.2, p.330-337, 2009.

SUEHIRO, et al. Vulnerabilidade ao estresse e satisfação no trabalho em profissionais do programa de saúde da família. v. 58, n. 129, p. 205-218, 2008.

YARKER, J.; DONALDSON-FEILDER, E.; FLAXMAN, P. Management competencies for preventing and reducing stress at work: Identifying and developing the management behaviours necessary to implement the HSE Management Standards. Health andSafetyExecutive Books. Recuperado em 22 de outubro de 2009 de http://www.hse.gov.uk/research/rrpdf/rr553.pdf.

TAMAYO, M.R., et al. Burnout no trabalho. Trabalho em transição, saúde em risco. Brasília, Editora Universidade de Brasília, p. 43-58, 2002.

CODO, W. Educação: Carinho e trabalho. Petrópolis: Vozes, 2000. 